\title{
Effects of passage and cryopreservation on neurotrophic factor secretion from choroid plexus epithelial cells
}

\author{
${\text { FENG } \mathrm{ZHAO}^{1 *}, \text { XIAO-YAN DING }}^{2 *}$, FENG WU $^{3}$, XIAO-HUI LI ${ }^{4}$, YU-HUAN LI ${ }^{5}$ and SHENG-LI HUANG ${ }^{5}$ \\ ${ }^{1}$ Department of Thoracic Surgery, The Second Affiliated Hospital, School of Medicine, Xi'an Jiaotong University, \\ Xi'an, Shaanxi 710004; ${ }^{2}$ Department of Ophthalmology, Xi'an No. 3 Hospital, Xi'an, Shaanxi 710018; \\ ${ }^{3}$ Department of Pathogenic Biology and Immunology, School of Medicine, Xi'an Jiaotong University, \\ Xi'an, Shaanxi 710061; ${ }^{4}$ Department of Radiology, The Second Affiliated Hospital, \\ School of Medicine, Xi'an Jiaotong University, Xi'an, Shaanxi 710004; \\ ${ }^{5}$ Department of Orthopedics, The Second Affiliated Hospital, School of Medicine, \\ Xi'an Jiaotong University, Xi'an, Shaanxi 710004, P.R. China
}

Received January 2, 2018; Accepted April 4, 2018

DOI: 10.3892/br.2018.1087

\begin{abstract}
The aim of the present study was to evaluate the effects of passage and cryopreservation of choroid plexus epithelial cells on their secretion of neurotrophic factors. Choroid plexus epithelial cells were cryopreserved and thawed following primary culture or passage cultured for up to two passages. The supernatant of primary, first/second passage and cryopreserved-thawed choroid plexus epithelial cells was collected when cells reached $80-90 \%$ confluence. ELISA was used to quantify brain-derived neurotrophic factor (BDNF), glial cell-derived neurotrophic factor (GDNF), nerve growth factor (NGF) and ciliary neurotrophic factor (CNTF) levels in the cell supernatant. First passage and cryopreserved-thawed cells secreted less BDNF and CNTF compared with primary cultured cells and increased levels of these two factors compared with second passage cells, and increased levels of GDNF and NGF compared with primary cultured and second passage cells (all $\mathrm{P}<0.05$ ). Therefore, first passage culture decreased BDNF and CNTF secretion but increased NGF and
\end{abstract}

Correspondence to: Professor Sheng-Li Huang, Department of Orthopedics, The Second Affiliated Hospital, School of Medicine, Xi'an Jiaotong University, 157 Xiwulu, Xi'an, Shaanxi 710004, P.R. China

E-mail: huangshengli@xjtu.edu.cn

*Contributed equally

Abbreviations: BDNF, brain-derived neurotrophic factor; CNTF, ciliary neurotrophic factor; DMEM, Dulbecco's modified Eagle's medium; DMSO, dimethyl sulfoxide; EGF, epidermal growth factor; FBS, fetal bovine serum; GDNF, glial cell-derived neurotrophic factor; NGF, nerve grow th factor

Key words: choroid plexus epithelial cells, neurotrophic factors, passage culture, cryopreservation
GDNF compared with primary culture; second passage culture diminished neurotrophic factor secretion compared with first passage culture; and cryopreservation did not weaken the function of choroid plexus epithelial cells in secreting BDNF, GDNF, NGF and CNTF. The current study demonstrates that first passage and cryopreserved-thawed choroid plexus epithelial cells have an enhanced function to secrete neurotrophic factors including BDNF, GDNF, NGF and CNTF.

\section{Introduction}

The choroid plexus, located within the brain ventricles, is a specialized structure consisting of epithelial cells and underlying vascular-rich connective tissues (1). Choroid plexus epithelial cells are involved in the production of cerebrospinal fluid, and secrete a number of neurotrophic factors including brain-derived neurotrophic factor (BDNF), glial cell-derived neurotrophic factor (GDNF), nerve growth factor (NGF) and ciliary neurotrophic factor (CNTF) (2-4). The neurotrophic factors are known to stimulate neuronal growth and promote neurite outgrowth (5). Depletion of these neurotrophic factors has been associated with pathologies and symptoms of Parkinson's, Alzheimer's and Huntington's diseases and spinal cord injury, and replacement strategies are considered as potential therapeutics for these neural degenerative diseases (3).

In recent years, cell transplantation therapy has emerged as a promising therapeutic option for neurorepair (6). Transplantation of choroid plexus epithelial cells from primary culture has been tested in several animal models, including rat models of Parkinson's disease, spinal cord injury and cerebral ischemia (7-9). However, cells are difficult to obtain in primary culture, and therefore the source of cells is limited. This problem may be overcome if passage culture and cryopreserved-thawed cells can be used for transplantation. This may depend on whether passage culture and cryopreservation impair the secretion of neurotrophic factors from choroid plexus epithelial cells. 
To the best of our knowledge, there has been no investigation into the effects of passage culture and cryopreservation on neurotrophic factor secretion from choroid plexus epithelial cells. The present study was conducted to compare the levels of BDNF, GDNF, NGF and CNTF secreted by neonatal rat choroid plexus epithelial cells among primary, first passage and second passage cultures and cryopreserved-thawed cells.

\section{Materials and methods}

Animals and reagents. Neonatal male Sprague-Dawley rats (1-day-old, weighing 5-6 g) and their mothers were supplied by the Center of Experimental Animals, Xi'an Jiaotong University (Xi'an, China). All rat mothers were housed individually with their offspring in polypropylene cages in a standard animal room maintained at $22 \pm 3^{\circ} \mathrm{C}$ and $50 \pm 20 \%$ humidity, and allowed access to food and water ad libitum under a natural day/night cycle. The experiments were performed with 24 rat offspring. The protocols for animal care and experimental management were approved by the Xi'an Jiaotong University Animal Experimentation Committee. Ethical approval for the study was obtained from the Ethics Committee of the Second Affiliated Hospital of Xi'an Jiaotong University.

Dulbecco's modified Eagle's medium (DMEM, low glucose) and fetal bovine serum (FBS) were purchased from Thermo Fisher Scientific, Inc. (Waltham, MA, USA), and 6-well plates were obtained from Corning Inc. (Corning, NY, USA). Recombinant rat epidermal growth factor (EGF) was obtained from PeproTech, Inc., (Rocky Hill, NJ, USA). ELISA kits for BDNF (cat. no. F15100), GDNF (cat. no. F15600), NGF (cat. no. F16310) and CNTF (cat. no. F15220) and normal goat serum were obtained from Shanghai Xitang Biological Technology Co., Ltd. (Shanghai, China). Dimethyl sulfoxide (DMSO) and trypan blue were obtained from Sigma-Aldrich (Merck KGaA, Darmstadt, Germany).

Primary culture. Primary culture of choroid plexus epithelial cells was prepared via the procedures described in our previous studies $(10,11)$. Briefly, following euthanasia with an overdose of pentobarbital $(150 \mathrm{mg} / \mathrm{kg}$, intraperitoneal injection) and disinfecting with $75 \%$ ethanol, the rat brains were isolated and the choroid plexus was removed from the lateral ventricles. The tissues were segregated into small cell aggregates by a mechanical method, and cultured in DMEM supplemented with $10 \% \mathrm{FBS}$ and $10 \mathrm{ng} / \mathrm{ml}$ EGF on 6 -well plates at $37^{\circ} \mathrm{C}$ in a humidified incubator at $5 \% \mathrm{CO}_{2}$. The culture medium was replaced every 2 days.

Passage culture and cell cryopreservation. When primary culture cells reached $\sim 90 \%$ confluence, cells were detached with a $0.25 \%$ Trypsin-EDTA solution. Cell numbers were determined with a hemocytometer. The viability of cells was assessed by trypan blue exclusion test (12). Then, cells were divided into two equal groups: One group was used for cryopreservation, and the other group was seeded into 6-well plates at a density of $1.5 \times 10^{3}$ cells $/ \mathrm{ml}$ with DMEM containing $10 \%$ FBS, and incubated in a $37^{\circ} \mathrm{C}, 5 \% \mathrm{CO}_{2}$ incubator. The culture medium was replaced as before every 2 days. When first passage culture cells reached $\sim 90 \%$ confluence, the second passage was initiated and performed as above.
Cryopreservation and thawing of cells. Choroid plexus epithelial cells collected from the previous steps were aliquoted at a density of $2 \times 10^{6}$ cells/cryovial with DMEM containing $90 \% \mathrm{FBS}$ and $10 \%$ DMSO. Cryovials with primary cultures were incubated sequentially at $4^{\circ} \mathrm{C}$ for $0.5 \mathrm{~h},-20^{\circ} \mathrm{C}$ for $2 \mathrm{~h}$, and $-80^{\circ} \mathrm{C}$ for $16 \mathrm{~h}$, and then transferred to and stored in a liquid nitrogen tank $\left(-196^{\circ} \mathrm{C}\right)$ until use. After 14 days of cryopreservation, the cells were thawed in a $37^{\circ} \mathrm{C}$ water bath $(\sim 1 \mathrm{~min})$. Upon thawing of the cells, the cryovial was removed from the water bath and the cells were transferred to a centrifuge tube containing $6 \mathrm{ml}$ DMEM containing $10 \%$ FBS. Following centrifugation at $1,000 \mathrm{x} \mathrm{g}$ for $5 \mathrm{~min}$ at room temperature, cells were resuspended with $9 \mathrm{ml}$ complete medium and dispensed into a 6 -well plate at a density of $1.5 \times 10^{3}$ cells $/ \mathrm{ml}$. Thereafter, culture medium was replaced every 2 days.

Light microscopy. All cultured cells were examined daily for growth under a phase contrast microscope (Olympus Corporation, Tokyo, Japan).

Monitoring of secretion function. Each culture of cells was maintained in an incubator at $37^{\circ} \mathrm{C}$ with $5 \%$ humidified $\mathrm{CO}_{2}$. Supernatant was collected when cells reached $80-90 \%$ confluence (within 2 days), and was conserved at $-70^{\circ} \mathrm{C}$ following centrifugation at $1,000 \mathrm{x}$ g for $5 \mathrm{~min}$ at room temperature. The samples were thawed at $4^{\circ} \mathrm{C}$ for $24 \mathrm{~h}$, then tested with the rat BDNF, GDNF, NGF and CNTF ELISA kits at room temperature. The values were expressed in $\mathrm{pg} / \mathrm{ml}$. At least four samples were analyzed for each culture.

Data analysis. Data were expressed as the mean \pm standard deviation. All statistical analyses were performed using GraphPad Prism 5.1 (GraphPad Software, Inc., La Jolla, CA, USA). One-way analysis of variance was performed for statistical evaluation, followed by the Newman-Keuls multiple comparisons test for stepwise multiple comparisons among the culture groups. $\mathrm{P}<0.05$ was considered to indicate statistical significance.

\section{Results}

Morphology of cultures. There were no obvious differences in morphological features among the primary cultured, first passage, second passage and cryopreserved-thawed cells under phase contrast microscopy. Choroid plexus epithelial cells grew in fusiform or exhibited polygon shape prior to fusion (Fig. 1).

Change of neurotrophic factors. First passage and cryopreserved-thawed cells secreted less BDNF and CNTF compared with primary cultured cells and increased levels of these two factors compared with second passage cells, and increased levels of GDNF and NGF compared with primary cultured and second passage cells (Fig. 2), with the differences deemed to be significant $(\mathrm{P}<0.05)$. These results suggested that first passage culture could decrease secretion of the neurotrophic factors BDNF and CNTF but increase that of NGF and GDNF, while second passage culture diminished secretion of all four neurotrophic factors. Cryopreserved-thawed cells 

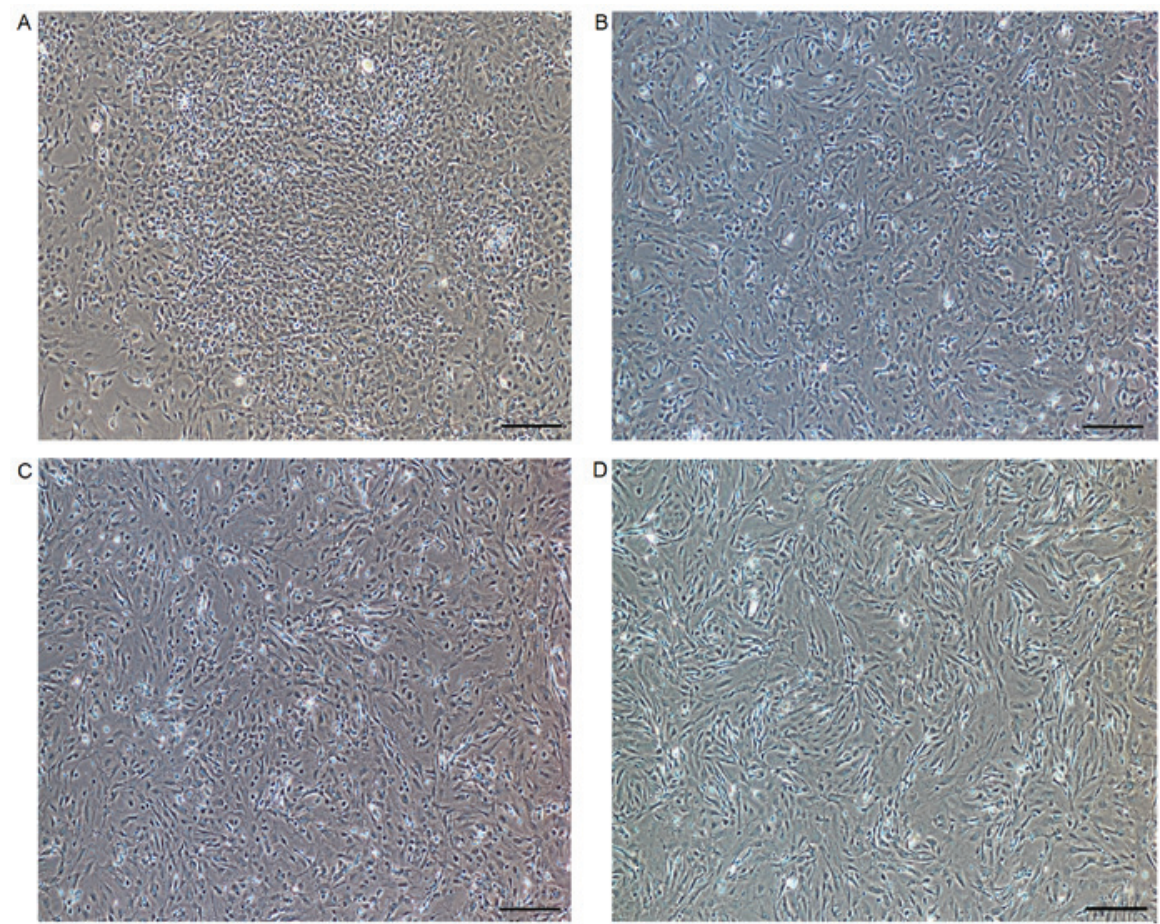

Figure 1. Choroid plexus epithelial cells grew in fusiform or with polygon morphology prior to fusion when observed by phase contrast microscopy (magnification, x100; scale bar, $200 \mu \mathrm{m}$ ). Representative images are shown of (A) primary culture, (B) first passage culture, (C) cryopreserved-thawed cells and (D) second passage culture.

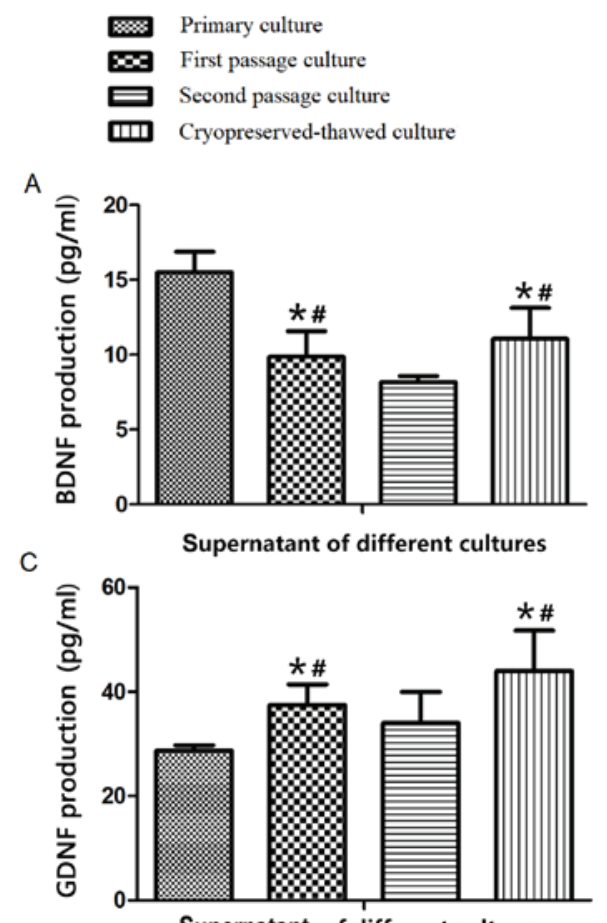

Supernatant of different cultures
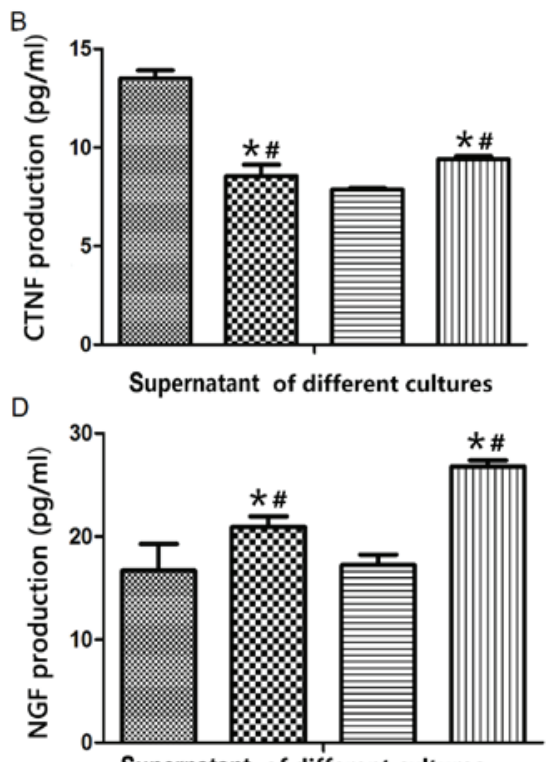

Supernatant of different cultures

Figure 2. Release of BDNF, CNTF, GDNF and NGF into the cell supernatant of different cultures. Graphical representation of (A) BDNF, (B) CNTF, (C) GDNF and (D) NGF secretion into the culture supernatant is shown. ${ }^{*} \mathrm{P}<0.05$ vs. primary culture; ${ }^{*} \mathrm{P}<0.05$ vs. second passage culture. BDNF, brain-derived neurotrophic factor; CNTF, ciliary neurotrophic factor; GDNF, glial cell-derived neurotrophic factor; NGF, nerve growth factor.

secreted the four factors at similar levels to first passage cells $(\mathrm{P}>0.05)$, indicating that cryopreservation did not weaken the function of choroid plexus epithelial cells in secreting neurotrophic factors.

\section{Discussion}

The present in vitro study demonstrated, to the best of our knowledge for the first time, the effects of passage culture 
and cryopreservation on the function of choroid plexus epithelial cells in secreting the neurotrophic factors BDNF, GDNF, NGF and CNTF. The levels of NGF and GDNF released by first passage and cryopreserved-thawed cells were higher compared with those from primary cultured cells, indicating that the function of the cells in secreting certain neurotrophic factors may be enhanced by first passage culture and cryopreservation. In the present study, supernatant was collected when cultured cells reached $80-90 \%$ confluence. At this time point, secretion of neurotrophic factors from choroid plexus epithelial cells was expected to be maximal, as the quantity of cells was sufficient and there was no contact inhibition, and the data should therefore reflect the total secretion function.

Primary cultures have been used in transplantation studies for spinal cord injury therapy $(8,13)$. It has been revealed that neurotrophins are key to the therapeutic effects (14). BDNF, GDNF and NGF are important for the survival, maintenance and regeneration of specific neuronal populations in the adult brain and spinal cord $(15,16)$. CNTF, which is widely distributed in the neuronal system, has nutritional function $(17,18)$. Transplantation of primary cultures of choroid plexus epithelial cells has been examined in rats with spinal cord injury, as a therapy to accelerate locomotor improvement and tissue repair including axonal extension in spinal cord lesions $(8,19)$. Studies suggest that the therapeutic effect may be linked with the cultured cells' function of secreting neurotrophic factors including BDNF, GDNF, NGF and CNTF $(4,20)$. However, cells are difficult to obtain in primary culture and the cell source for transplantation is thus limited. If passage cultured and cryopreserved cells can be demonstrated to secrete neurotrophic factors in high quantities, they maybe used for transplantation and the shortage of choroid plexus epithelial cells can be overcome.

The cells in the current study were passage cultured up to second passage and neurotrophic factors were quantified for only three generations. Therefore, the data do not offer a trend to elucidate the effect of continuous passage culture. In future study, the passage cultured cells and cryopreserved choroids plexus epithelial cells should be applied in spinal cord injury models, to determine the efficacy of both cell transplantation and purified neurotrophic factors.

In conclusion, first passage cultured and cryopreserved-thawed choroid plexus epithelial cells may secrete high levels of neurotrophic factors, among which the levels of NGF and GDNF may be higher than those secreted by primary cultured cells. Second passage cells secrete comparatively less neurotrophic factors. Based on the present results, first passage and cryopreserved-thawed cells may have therapeutic potency in the treatment of neural degenerative diseases and could be adopted in the future.

\section{Acknowledgements}

Not applicable.

\section{Funding}

The present study was supported by research grants from the National Natural Science Foundation of China (grant no. 81471247) and the Science and Technology Project of Xi'an, China [grant no. 2016048SF/YX04 (3)].

\section{Availability of data and materials}

All data generated or analyzed during this study are included in this published article.

\section{Authors' contributions}

FZ, XYD, FW, XHL and YHL performed the experiments and analyzed the data. FZ wrote the original manuscript. SLH designed the research. All authors read and approved the final manuscript.

\section{Ethics approval and consent to participate}

The protocols for animal experiments were approved by the Xi'an Jiaotong University Animal Experimentation Committee (Xi'an, China).

\section{Consent for publication}

Not applicable.

\section{Competing interests}

The authors declare that they have no competing interests.

\section{References}

1. Santos CR, Duarte AC, Quintela T, Tomás J, Albuquerque T, Marques F, Palha JA and Gonçalves I: The choroid plexus as a sex hormone target: Functional implications. Front Neuroendocrinol 44: 103-121, 2017.

2. Chodobski A and Szmydynger-Chodobska J: Choroid plexus: Target for polypeptides and site of their synthesis. Microsc Res Tech 52: 65-82, 2001.

3. Damkier HH, Brown PD and Praetorius J: Cerebrospinal fluid secretion by the choroid plexus. Physiol Rev 93: 1847-1892, 2013.

4. Huang SL, Wang J, He XJ, Li ZF, Pu JN and Shi W: Secretion of BDNF and GDNF from free and encapsulated choroid plexus epithelial cells. Neurosci Lett 566: 42-45, 2014.

5. Scheepens A, Sirimanne ES, Breier BH, Clark RG, Gluckman PD and Williams CE: Growth hormone as a neuronal rescue factor during recovery from CNS injury. Neuroscience 104: 677-687, 2001.

6. Feng YP, Sun TS, Chen L, Xie JX, Zhang ZC, Huang HY and He XJ: Clinical therapeutic guideline for neurorestoration in spinal cord injury (Chinese version 2016). J Neurorestoratology 5: 73-83, 2017.

7. Zhang HL, Wu JJ, Ren HM, Wang J, Su YR and Jiang YP: Therapeutic effect of microencapsulated porcine retinal pigmented epithelial cells transplantation on rat model of Parkinson's disease. Neurosci Bull 23: 137-144, 2007.

8. Kanekiyo K, Nakano N, Noda T, Yamada Y, Suzuki Y, Ohta M, Yokota A, Fukushima M and Ide C: Transplantation of choroid plexus epithelial cells into contusion-injured spinal cord of rats. Restor Neurol Neurosci 34: 347-366, 2016.

9. Borlongan CV, Skinner SJ, Geaney M, Vasconcellos AV, Elliott RB and Emerich DF: CNS grafts of rat choroid plexus protect against cerebral ischemia in adult rats. Neuroreport 15: $1543-1547,2004$.

10. Huang SL, He XJ, Li ZF, Yao L and Shi W: A novel primary culture method for rat choroidal epithelial cells. Neurosciences (Riyadh) 18: 27-32, 2013.

11. Huang SL, He XJ, Li ZF, Yao L, Yuan GL and Shi W: Primary culture of choroid plexuses from neonate rats containing progenitor cells capable of differentiation. Balkan Med J 30: 350-354, 2013. 
12. Liu JJ, Ding XY, Xiang L, Zhao F and Huang SL: A novel method for oxygen glucose deprivation model in organotypic spinal cord slices. Brain Res Bull 135: 163-169, 2017.

13. Ide $\mathrm{C}$ and Kanekiyo K: Points regarding cell transplantation for the treatment of spinal cord injury. Neural Regen Res 11: 1046-1049, 2016

14. Thanos CG, Bintz BE, Goddard M, Boekelheide K, Hall S and Emerich DF: Functional modulation of choroid plexus epithelial clusters in vitro for tissue repair applications. Cell Transplant 20: $1659-1672,2011$.

15. Allen SJ, Watson JJ, Shoemark DK, Barua NU and Patel NK: GDNF, NGF and BDNF as therapeutic options for neurodegeneration. Pharmacol Ther 138: 155-175, 2013.

16. Zhao YZ, Jiang X, Xiao J, Lin Q, Yu WZ, Tian FR, Mao KL, Yang W, Wong HL and Lu CT: Using NGF heparin-poloxamer thermosensitive hydrogels to enhance the nerve regeneration for spinal cord injury. Acta Biomater 29: 71-80, 2016.
17. Louis JC, Magal E, Takayama S and Varon S: CNTF protection of oligodendrocytes against natural and tumor necrosis factor-induced death. Science 259: 689-692, 1993.

18. Gu YL, Gao GQ, Ma N, Ye LL, Zhang LW, Gao X and Zhang ZB: CNTF protects neurons from hypoxic injury through the activation of STAT3pTyr705. Int J Mol Med 38: 1915-1921, 2016.

19. Emerich DF, Vasconcellos AV, Elliott RB, Skinner SJ and Borlongan CV: The choroid plexus: Function, pathology and therapeutic potential of its transplantation. Expert Opin Biol Ther 4: 1191-1201, 2004.

20. Han Y and Kim KT: Neural Growth Factor Stimulates Proliferation of Spinal Cord Derived-Neural Precursor/Stem Cells. J Korean Neurosurg Soc 59: 437-441, 2016. 